SO

4,3

204

\title{
Understanding transition performance during offshore IT outsourcing
}

\author{
Erik Beulen \\ Tilburg University, Tilburg, The Netherlands and \\ KPMG EquaTerra, Tilburg, The Netherlands \\ Vinay Tiwari \\ Shell, The Hague, The Netherlands, and \\ Eric van Heck \\ Rotterdam School of Management, Erasmus University, \\ Rotterdam, The Netherlands
}

\begin{abstract}
Purpose - Within an IT outsourcing relationship, transition represents a critical and complex phase that starts immediately after contract signing. Transition involves handing over outsourced activities from client firm to service provider firm and accompanies a new way of operating. The purpose of this paper is to determine and detail factors influencing the performance of transition phase within global IT outsourcing relationships.

Design/methodology/approach - In this paper, the authors present a framework for transition performance that includes four factors: transition planning, knowledge transfer, transition governance and retained organization. This framework is tested and enriched by utilizing a single, in-depth case study involving over 25 interviews with a global offshore IT outsourcing engagement.

Findings - It was found that knowledge transfer and transition governance are more critical factors than transition planning and retained organization for transition performance. This was due mainly to two reasons: the critical challenges faced, within the scope of these factors, had higher potential to disrupt transition; and both these factors and their related issues required a significant joint and coordinated effort from client and service provider firms, thereby, making implementation challenging for transition.

Originality/value - Practitioners have suggested that over two-thirds of failed outsourcing relationships are due to transition-related challenges. This paper represents one of the first in-depth studies that provides insights from a real-life global outsourcing engagement, which contributes to and complements existing literature on IT outsourcing by providing a greater understanding of transition. Furthermore, it provides practitioners with insights and best practices that can be used to guide transitions in real-life engagements.
\end{abstract}

Keywords Strategic outsourcing, Information technology, Outsourcing, Transition management, IT offshoring, IT outsourcing, Governance

Paper type Case study

\section{Introduction}

The IT outsourcing industry has been growing for decades and is resulting in new business models (Khan and Fitzgerald, 2004; Willcocks and Lacity, 2006; Lacity and Rottman, 2008; Rivard and Aubert, 2008). According to IDC, worldwide IT spending has experienced an annual compounded growth rate of more than 5 per cent since 1995, 
reaching almost USD1.5 trillion in 2009 (Minton, 2010). The term "outsourcing" reflects the use of external agents to perform one or more organizational activities, and "IT outsourcing" refers to handing over the responsibility for the execution of IT services to an external service provider (Lacity and Hirschheim, 1993). Transition is a pre-requisite to implementing an outsourcing decision successfully (Ross et al., 2005). Transition is immediately followed by contract signing and precedes the service delivery phase. It involves handover of outsourced services from either the client's internal IT department or the incumbent service provider to the new service provider. Transitions take on average two to three months. A transition include critical stages such as conducting knowledge transfer, determining new governance structures, and applying the processes of the service provider (Parikh and Gokhale, 2006, p. 144).

According to Lacity and Willcocks (2000, p. 23), the objective of the transition phase is to achieve operational performance, and it includes activities such as validating service scope, costs, levels, and responsibilities for baseline services, and fostering realistic expectations of supplier performance. Cullen and Willcocks (2003, p. 151) define transition as "implementing the new way of operating". Experts consider transition to be the most critical phase for overall success of an outsourcing relationship (Carmel and Tjia, 2005). The cost of transition is substantial and ranges from 2 to 15 per cent of the total cost of the first year of the outsourcing deal (Ambrose and Matlus, 2005). Critical transition issues are sometimes overlooked during contract negotiations (Beulen et al., 2011, p. 45) and are difficult to manage (Beulen et al., 2009). According to CIO Magazine, over two-thirds of failed outsourcing relationships arise due to inappropriate or poor transition (Robinson and Iannone, 2007). Transition failure is a risk for IT outsourcing (Lacity et al., 2009). Transferring knowledge in offshore IT outsourcing relationships is even harder (Gupta et al., 2007; Kotlarsky et al., 2007; Oshri et al., 2007). An important reason for the increased complexity of transferring knowledge in offshore IT outsourcing relationships still is the cultural difference (Carmel, 1999; Beulen et al., 2011, p. 97). This might be bridged by training prior to the start of the transition (Carmel and Beulen, 2005, p. 148).

Despite having an enormous bearing on the outcome of outsourcing relationship, studies within the IS outsourcing (or offshore outsourcing) domain on transition phase are lacking in academic research. In this study, we adopt the following research question:

$R Q 1$. What factors influence transition performance and why?

To investigate this question, based on extant literature, including knowledge management literature, we developed a framework for transition performance involving four factors - transition planning, knowledge transfer, transition governance and retained organization. Next, we selected an offshore outsourcing engagement and followed it closely: before, during and after transition, and collected data using several formal and informal interviews, site observations and project documents.

In the next section, we discuss the context of transition. Subsequently, we provide the theoretical background for the factors influencing transition performance, followed by the methodology and findings from the study. Thereafter, we discuss the findings and avenues for future research.

\section{Understanding transition performance}

205 
SO

4,3

206

\section{Transition phase}

A typical IS outsourcing relationship (Figure 1) can broadly be divided into six phases initiation, service provider selection, contract negotiation, transition, service delivery and contract renewal/termination (borrowed from Lacity and Willcocks (2000) and Cullen and Willcocks (2003), and modified). While the first three phases are referred to as pre-execution stages, the two following phases, transition and service delivery, are referred to as execution stages of an IS outsourcing relationship. The last phase, contract renewal or termination, refers to the reconsideration of future of the relationship, which might end or continue with a revised contract.

\section{Knowledge transfer}

Knowledge management is a key topic within the fields of international business and management information systems. Friedman (2005, p. 189) concluded that:

[...] international business contributions include a broad set of increasingly well-understood influences on the factors associated with knowledge transfer particularly market and country levels; MIS contributions include models of mechanisms by which such knowledge can be effectively distributed. In the area of outsourcing and most particularly IT offshoring, international contributions include providing a broad set of variables that influence the more general decisions regarding work location.

Park et al. (2011, p. 54) define knowledge transfer as the extent to which clients acquire, absorb, and utilize knowledge on outsourced IT from vendors.

During transition, knowledge transfer is key (Blumenberg et al., 2009). In the transition from the outsourcers and their providers, there are two types of knowledge transfer: services are transferred from the provider to the outsourcer, and the organization-specific knowledge regarding processes and procedures is transferred from the outsourcer to the provider (Quinn, 1999). The transfer of services is defined as technical knowledge by Park et al. (2011). In transitions, IT outsourcer staff can be transferred to the service provider (Grimshaw and Miozzo, 2009). This can be based on legal regulations such as transfer of undertakings (protection of employment) (TUPE) and Acquired Rights Directive (ARD) or on mutual agreement of the outsourcer, the provider and the involved IT staff. However, in offshore outsourcing engagements, the transfer of IT staff is very rare.

\section{Theoretication background: transition performance}

In this section, we develop an initial framework of transition performance. This framework is based on the current literature available on transition and is further supplemented by the professional experience of the authors. We specifically focus

Figure 1.

Outsourcing relationship lifecycle

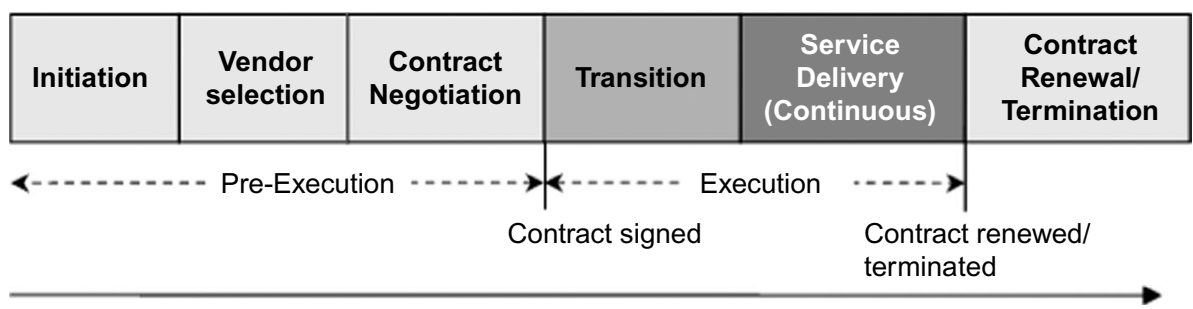

Time 
on four factors - transition planning, knowledge transfer, transition governance, and retained organization. These four factors influence transition performance. The factor transition planning is impacting the three other factors. This research is applied in an offshore outsourcing engagement (Figure 2).

\section{Transition planning}

Transition during outsourcing relationships has a clear starting and end point, with well-defined deliverables (Cullen and Willcocks, 2003), and can be characterized as a project. It is well known that complex projects require significant time for a thorough planning and preparation (Cadle and Yeates, 2008). The project management office (PMO), of client organizations, usually takes the responsibility of developing transition plan. The PMO has a lot of knowledge of the client organization to facilitate projects (Desouzaa and Evaristob, 2006). Transition planning is developed jointly with consultation between the client and the service provider organization. We identified four important sub-factors related to project planning, namely, dependencies with other projects, qualified resources to execute the project, quality of the transition plan, and compliancy with other contractual or industry-specific regulatory obligations.

Project interdependencies. Client organizations, while planning for an outsourcing relationship and its transition, need to keep other possible projects (such as software package implementations or hardware installations) and their interdependencies under consideration (Verma and Sinha, 2002). These interdependencies, if not handled properly during planning, can negatively impact the transition.

Identification of resources. Managing complex projects, such as transition, requires specialized and capable resources from both client and service provider (Karimi et al., 2007). Capable client and service provider personnel need to be identified prior to the transition. These resources are required to ensure that a proper knowledge transfer takes places.

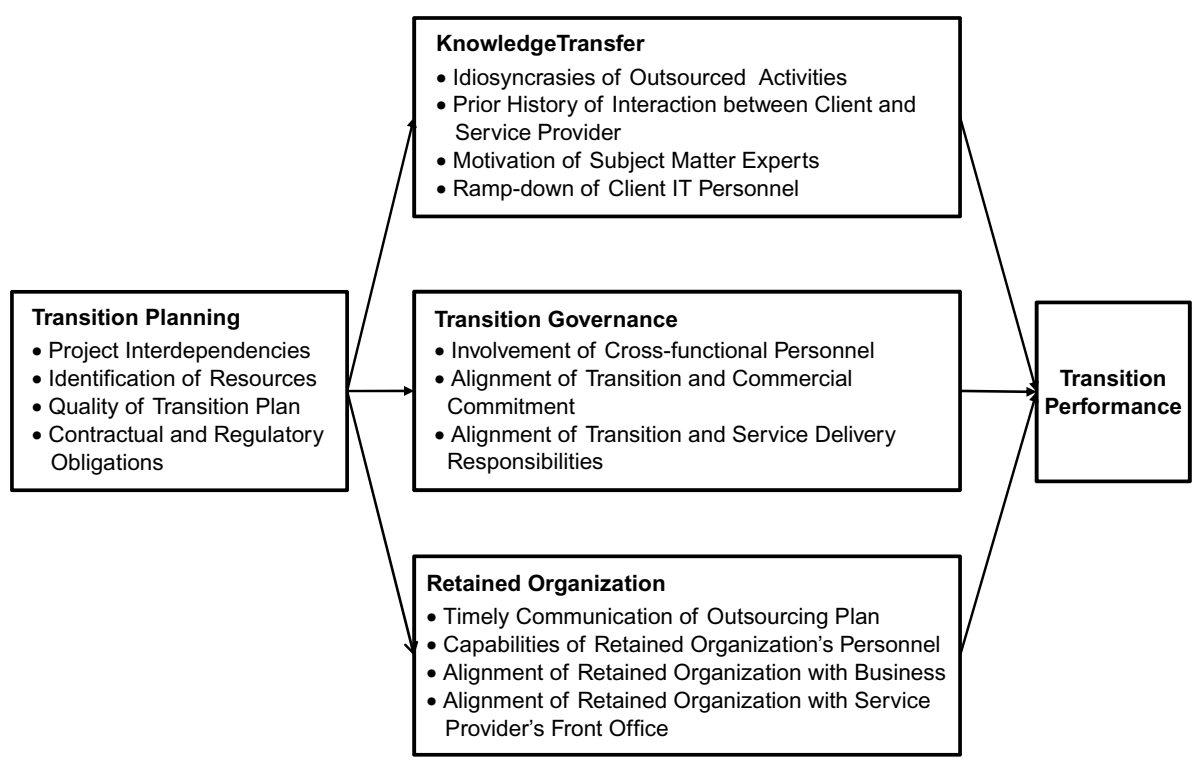

Understanding transition performance

207
Figure 2.

Theoretical framework of transition performance 
SO

4,3

208

Quality of transition plan. A thoroughly prepared transition plan, jointly agreed upon by both client and service provider, is essential for a smooth transition (Cullen and Willcocks, 2003). The plan describes various sub-stages within the transition period, the roles and responsibilities of both firms, and the transition deliverables (Ambrose and Matlus, 2005).

Contractual and regulatory obligations. As an outsourcing relationship involves contractual agreements between two firms, transition planning needs to consider any potential conflict with other contractual or regulatory obligations (Vroom and Solms, 2004). Detecting any conflicts at later stages would severely impact transition and the entire outsourcing relationship.

\section{Knowledge transfer}

Knowledge transfer represents one of the most critical activities during the transition period of any outsourcing relationship (Cullen and Willcocks, 2003; Carmel and Tjia, 2005; Oshri et al., 2007). Service provider IT personnel working on the engagement are flown in from their respective offshore locations to the client location for intensive knowledge transfer sessions. Client firm subject matter experts, who specialize in their domain within the broader IS system being outsourced, host these knowledge transfer sessions. We identified four sub-factors related to knowledge transfer that influence the transition - idiosyncrasies of outsourced activities, prior history of interaction between client and service provider, job insecurity of subject matter experts, loss of knowledge due to ramp-down of client IT personnel.

Idiosyncrasies of outsourced activities. This refers to the specific or customized processes existing in the client organization or their IS systems that differ from an industry-wide standard perspective (Wang et al., 1997). Service provider personnel visiting client locations for knowledge transfer sessions are experts and possess general knowledge about the particular technical or functional area related to the outsourced systems. What they lack, however, is experience with the specifics of the client's IS systems and related processes, and an understanding of these specifics is necessary for a successful transition.

Prior history of interaction between client and service provider. Any previous experience between firms influences their perceptions related to motivation, trust and capabilities towards the other (Levina and Ross, 2003). These perceptions, to a certain extent, determine their behaviour during knowledge transfer planning and execution.

Motivation of subject matter experts. The motivation of subject matter experts to transfer knowledge is a crucial aspect within knowledge transfer. Their motivation is influenced by, inter alia, feeling of job insecurity and loss of control (Cullen and Willcocks, 2003). Close collaboration from subject matter experts, who might get replaced by the service provider personnel they are training, is necessary for knowledge transfer sessions to be productive.

Ramp-down of client IT personnel. The implication of an outsourcing relationship includes a reduction in the strength of the client's IT department. An uncontrolled or poorly planned ramp-down of a client's IT personnel, specifically subject matter experts, can lead to the loss of knowledge to be transferred to the service provider personnel (Goles, 2006), thereby influencing the success of knowledge transfer sessions and transition. 
Transition governance

Transaction cost economics provides us with the basic foundational knowledge that formal governance mechanisms, such as contracts, are essential in alleviating known exchange hazards, such as uncertainty in inter-organizational relationships (Williamson, 1991). Other scholars have emphasized the importance of relational governance mechanisms, focussing on issues of trust and social identification (e.g. direct frequent contact, establishing joint teams, etc.) for managing even complex relationships, and they largely view relational governance as a complement for explicit contracts (Lacity et al., 2010) instead of a substitute (Dyer and Singh, 1998). Within IS outsourcing relationships, official contracts are accompanied by several control and coordination modes and mechanisms employed by organizations, such as formal controls (behaviour and outcome control and informal controls), self-control, and clan control in order to ensure that service provider organizations act as desired (Choudhury and Sabherwal, 2003).

We identified four sub-factors within transition governance, namely, involvement of cross-functional or multi-disciplinary personnel from both client and service providers, alignment of transition responsibility and commercial commitment, and alignment of transition responsibility and service delivery responsibility.

Involvement of cross-functional personnel. As transition represents the first few weeks of an outsourcing relationship both for client and service providers, involvement of cross-functional teams (such as design, development, maintenance, functional, technical, etc.) from both sides becomes important for interfacing and providing a holistic perspective (Feeny and Willcocks, 1998). Lack of cross-functional team involvement or cooperation from either side hampers communication and coordination, thereby, influencing the transition.

Alignment of transition responsibility and commercial commitment. The cost of transition is determined during contractual negotiations, in terms of budgeted number of man-days required for performing the transition. In contractual negotiations service providers might decide to reduce the price of the service provisioning by reducing the price of the transition. As the transition is one time effort reducing the price of transition is impacting the service providers less than reducing the price of the multi-year service provisioning. Regardless of the commercial commitment that is finally agreed upon during the contractual negotiations, the transition manager needs a budgeted number of man-days in order to implement the transition. This tension between completing transition within the budgeted time period creates challenges, thereby influencing the transition.

Alignment of transition responsibility and service delivery responsibility. Once transition is complete, engagement moves into the service delivery phase (Figure 1). To prepare for the service delivery responsibility, strong cooperation between the transition manager, responsible for the transition, and the service delivery manager, responsible for the service delivery, is a prerequisite. It is extremely important for the entire outsourcing relationship that transition responsibilities and service delivery responsibilities are closely aligned by involving and updating the service delivery manager throughout transition. Also, transition holds a priority over service delivery; therefore, the transition manager overrides the service delivery manager during the transition period (Beulen, 2008). A proper alignment between transition responsibility and service delivery responsibility becomes critical to the overall transition performance.
Understanding transition performance

209 
$\mathrm{SO}$

4,3

210
Retained organization

Establishing and ensuring the stability and continuity of the service delivery phase following transition period is an important transition goal. This requires setting up and utilizing a capable retained organization at the client firm (Lacity and Hirschiem, 1993; Gottschalk and Solli-Saether, 2006). We identified four important sub-factors related to the retained organization, namely, timely communication of the outsourcing plan to all relevant personnel at the client firm, capabilities of personnel within the retained organization, alignment of the retained organization with the business at the client firm, and alignment of the retained organization with the service provider's front office.

Timely communication of outsourcing plan. Appropriate communication and change management initiatives related to outsourcing impact personnel motivation level at the client firm (Cullen and Willcocks, 2003). Managing expectations and providing clarity about the expected post-outsourcing scenario to the client's IT personnel, especially those involved within the retained organization, is important to transition.

Capabilities of the retained organization's personnel. Client personnel who are part of the retained organization need to be capable of handling the changed processes accompanying the post-outsourcing scenario for a smooth service delivery (Feeny and Willcocks, 1998). Training existing personnel or recruiting additional resources can strengthen the retained organization.

Alignment of the retained organization with business. Aligning changed processes within the newly developed retained organization, which acts as a customer to client's IT department, and business are essential to ensure business continuity during and after transition (Ambrose and Maltus, 2005; Henderson and Venkatraman, 1993).

Alignment of the retained organization with the service provider's front office. Aligning roles, responsibilities and processes within client's retained organization with service provider's front office is crucial for communication and coordination between the two firms during entire outsourcing relationship (Lacity and Willcocks, 2000). This alignment assumes the importance of several engagement-specific purposes, such as distinguishing accountability and clear escalation processes, to ensure smoother transition.

\section{Methodology}

We chose a single case study approach to address the $R Q 1$. This was primarily due to the limited academic literature available on transition, and to ensure an appropriate fit of the approach with the objective of understanding transition in a real-life offshoring context. Case studies form an ideal approach when boundaries of a complex phenomenon (i.e. transition) are connected closely with the context (i.e. offshoring) (Eisenhardt, 1989; Yin, 2002). Furthermore, case study approaches are widely used by IS scholars due to the richness of data available, which thus enables determining "local causality" (Miles and Huberman, 1994, p. 15) and suitability for building theory on emergent phenomenon (Eisenhardt and Graebner, 2007).

Data collection and analysis

We collected data for this study through semi-structured interviews, notes from informal discussions, extensive project documents, observations from visits to the project sites and e-mail correspondence from August 2007 through May 2008. We conducted formal 
interviews using semi-structured interview protocol, which we provided to interviewees in advance. In total, 25 of these interviews (the Appendix) were audiotaped with permission, accompanied by extensive notes taken by both the authors. All taped audios were fully transcribed for data analysis purposes. The average duration of an interview is approximately 60 minutes, with a minimum interview duration of 35 minutes and a maximum of 180 minutes. Informal discussions and interesting observations gathered from time spent at project sites were not audio taped but written down as notes, mostly after the conversation or visit, but on the same day. Several key informants were interviewed multiple times during various stages of the project to understand major developments and their impact on the Customer Project.

\section{Case description}

The case involves an IT service provider (Accenture) and a European utility company (UtilCo[1]). UtilCo is a leading utilities firm that predominantly operates in a single country. It is a European organization; it employs a total workforce of $+10,000$, and serves +2.5 million customers. Accenture is a global IT outsourcing service provider. A US-based organization, it employs approximately 170,000 people and spreads over 50 countries, with a turnover of almost USD21.45 billion (2007). UtilCo's relationship with Accenture has been in existence over the last ten years.

The project under study, referred to as CUSTOMER, relates to a recently signed contract (August 2007) that involves an offshore component in their relationship. Until now, Accenture provided services mainly either at UtilCo's premises or at their closest delivery centre (in a neighbouring city). This Customer Project marks UtilCo's first experience with transferring certain IS activities to Accenture's offshore delivery centre. Accenture was rewarded with this contract as they prepared the best response to the request for proposal of the UtilCo. The management of the UtilCo was rather satisfied with the performance of Accenture although Accenture did not have a good reputation amongst UtilCo personnel. According to the contract, Accenture will begin to provide services mainly from their offshore delivery centre (based in India), reduce their team working at UtilCo's premises, and ramp up their facility at the offshore centre. In this engagement, around 50 FTEs are involved. The duration of the contract is two years, and it pertains to SAP application development and maintenance activities. The Customer Project involves three sites: UtilCo's site, Accenture's site near UtilCo (same country) and Accenture's distant site. Accenture personnel are to be distributed across all three sites: two European sites and one Indian site. The transition also impacted the UtilCo's personnel. Their roles and responsibilities changed as the nature of the contract with Accenture changed from an onshore outsourcing contract to an offshore outsourcing contract.

\section{Findings}

In this section, we present findings from the case study involving the Customer Project. We present these findings while verifying our framework from the case study data, where we verified our initial framework with a structured questionnaire and discussions with senior UtilCo personnel. In addition to analysing the factors and sub-factors of our framework, we also explored in our research new factors and sub-factors. These two new sub-factors will be presented in this findings section and analysed and discussed in more detail in the discussion section.

\section{Understanding transition performance}

211 
SO

4,3

212
Transition planning

Accenture is the main party responsible for the transition planning. In addition, transition planning capabilities were previously assessed during the Accenture selection process, and hence, were given less importance from UtilCo's perspective during this stage.

1. Project interdependencies. We found little evidence of any potentially significant conflict among various projects during transition. There was another service provider involved with UtilCo for outsourcing of different IS activities at the same time as the project under investigation. But both of these projects seemed well planned to avoid any issues with respect to interdependencies.

2. Identification of resources. During planning for transition, both UtilCo and Accenture identified and included most of their respective qualified and capable resources to interact with the other firm. From Accenture's perspective, they needed to involve resources that had experience with earlier transitions and that would grasp the know-how from UtilCo within the stipulated time. For them, the issue was not just about resource capability, but resource availability, as well.

The Transition Lead from Accenture's offshore site stated:

We have managed to get the first set of people, and we also had a few people from the earlier 10-member team but as we move on. I think there are still a few profiles that we need to locate. The way we also do is to take some of the people who may have not necessarily worked on Billing functionality, but have worked on other SAP modules. They actually undergo training and work on some shadow programs before they actually get on board (Interview with BN).

From UtilCo's perspective, as they had not experienced transition earlier, they needed to identify resources capable of not just carrying out knowledge transfer sessions, etc. but who also had the ability to track and monitor the entire transition period for various metrics (such as cost, resources utilized, timely delivery). Resource capability at UtilCo became a very critical issue as transition proceeded. IT Delivery Lead (senior IT management) from UtilCo stated:

From the start, onward, when I came in, I had a very strong feeling about the fact that the management working for DK (another senior management person) and myself were not experienced enough to manage such transition. And it's very important because, the quality of transition is something done and managed by them and not by me [...] so we hired someone to coordinate the whole process and set up a good core structure and, etc. [...] and it went well till the person left [...] and then we saw that the current UtilCo management was totally not in control (Interview with BG).

3. Quality of the transition plan. At several stages during transition, there was a need for joint and comprehensive planning. For instance, during the knowledge transfer phase, within two weeks of contract signing, Accenture was quick to bring in their personnel for knowledge transfer sessions at UtilCo's location. But UtilCo seemed ill-prepared for the situation, which led to a delay in subject matter experts availability for knowledge transfer sessions. Accenture's Onshore Project Lead stated:

They [service provider personnel for KT] were here for a month, in which we were able to schedule some kind of KT [...]. We were a lot quicker from our side than from the client side. So, we brought our people in, but the client wasn't ready yet for them and overwhelmed with it, and so scheduling the KT at the beginning for our offshore team was difficult (Interview with SV). 
Accenture's Offshore Project Lead resonated the same feeling when asked about challenges in planning with regard to knowledge transfer sessions:

The important thing in any knowledge transfer activity is to have a very concrete plan. It's very important in any project, esp[ecially] when we are talking about people going on shore, sitting over there, burning the budget and spending some time; so we need to have concrete planning. This is certainly one area of improvement that planning, in terms of SME availability from [Client's] perspective, was not very clear (Interview with NT).

Towards the later part of transition, when pilot projects were near completion, joint planning between UtilCo and Accenture was found lacking once again, as stated by Offshore Project Lead:

In my discussion with SV [the service provider's Onshore Project Lead], it came up that we should be ready for two types of work, and accordingly, we started planning because by $3^{\text {rd }}$ of January [end of pilot project], we knew that we are going to finish this last object, and after that, we have capacity available in the team. Again, some stringent planning is required from Client-side in terms that they knew that we have this kind of availability in the first week of January [...] but this was not utilized by the client (Interview with NT).

4. Contractual and regulatory obligations. There seemed no issue with regard to any contractual or regulatory obligations that were not fulfilled during the Customer Project. This was rather unexpected, as most firms face an increasing number of contractual and regulatory obligations.

5. Staged approach. In addition to the four sub-factors of our framework, we find a potential fifth sub-factor: staged approach. With regard to transition planning, we found that UtilCo preferred a staged approach for transition - proceeding in various sub-stages during transition rather than having complete handover of activities and responsibilities in a big bang fashion. Transitions should not be managed as a black box. Transitions should include as many check points as possible. UtilCo's Transition Lead mentioned:

We also had a clear focus [... ] we explicitly asked our partners to give us a proposal on how to go through this process. So we ask them on their view on how to take it up and make it successful. And I think that's where we already attended the stage approach, and by having a discussion with our partners, the stage approach got clearer because I think traditionally it's a big bang scenario. So you say the contract started and the contract partners are responsible to make sure that everything goes right (Interview WK).

UtilCo implemented this approach due to its past unsuccessful experience with another firm, as described by UtilCo's Transition Lead:

Well, we had an experience with [another service provider] on the infrastructure where we did the big bang scenario, and well, that was something we didn't want to follow this time around. So for me, this was also a given. But from our perspective in various discussions, this approach was developed. Also, we discussed it with some external senior consultants in this area of sourcing (Interview WK).

Also, as UtilCo was sceptical about allowing complete control to shift to Accenture, it became important to progress steadily, with UtilCo exercising and keeping control on the engagement. UtilCo's Transition Lead stated:
Understanding transition performance

213 
SO

4,3

214

And because of the theme of control that we discussed, you can only go through when you constantly feel in control. Well, sometimes you have to let it go, of course, because otherwise the situation will remain the same. By the stage approach that we chose, we could let it go, not in an abrupt way, but let it go on a sliding scale (Interview WK).

Since UtilCo asked for a staged approach, Accenture provided such a solution, with planning each sub-stage focussing on meeting entry and exit criteria. Accenture's Onsite Project Lead stated:

If I want to go forward to the next stage, it's more than just a financial way of working that is going to change, and responsibility as well. We are going to switch to managed service phase [towards April 2008] where we will take full responsibility for all instances that are locked on a certain pre-defined set of applications. We will take responsibility for all the activities in those areas. And that is also the end stage of our scope of activities. We have targets on cost efficiency [...] average number of lead-times for RFCs [request for change], the average number of man-days for functions points. We have targets for different stages to make sure that we can move on to another phase. We have to make sure that a certain cost reduction is achieved, that we have efficiency gains in there. Lead time reduce[s] things like that. So, that is our KPIs have been pre-defined in the context that we will monitor during different phases of our contract (Interview SV).

\section{Knowledge transfer}

We have indicated that knowledge transfer is the most important factor among all factors for the success of transitions. Most of the senior-level interviewees from both UtilCo and Accenture confirmed the importance of knowledge transfer. Offshore Transition Lead stated:

The most important step for us was the knowledge transfer phase; we were worried it might not go smoothly because of the short duration and some issues with SMEs, but it went fine (Interview with BN).

1. Idiosyncrasies of outsourced activities. This did not seem to be a serious concern in the Customer Project. Although, Offshore Project Lead did mention that the decision-making process at UtilCo related to outsourced activities seemed too complicated to understand:

When I was presented the structure at UtilCo within [the] IT Department, it was quite complex, which I'm not normally used to seeing. I think there are a lot of decision-making steps that create bottlenecks. Their structure can be normalized so that a lot of decisions can be easily taken or acted upon (Interview with NT).

2. Prior history of interaction between client and service provider. Past experience between the two firms played out in the Customer Project in two ways. First, Accenture did not have a good reputation among UtilCo personnel due to a previous engagement. UtilCo's Transition Lead stated:

Accenture has already a long history with us, a partner we know very well and who have given themselves somewhat of a negative image in our company. When I had those workshops [...] I told several times to SS [service provider's Onshore Transition Lead] [...] But we kept contact continuously open; getting those sharing and managing expectations continuously helps a lot in the success of the transition (Interview with WK).

Second, Accenture already knew a lot about the UtilCo's work culture and even technical and functional aspect of their systems due to previous engagements, 
which helped them significantly in formulating acceptable solutions, as explained by UtilCo's IT Delivery Lead:

We went for them [their solution] [... ] because it was very simple; it was a very clear solution in a commercial - very transparent [way] (Interview with BG).

3. Motivation of subject matter experts. Subject matter experts play a critical role in knowledge transfer sessions, as they are the experts who transfer to and share knowledge with incoming Accenture's personnel. During the course of the engagement, Accenture personnel were to replace Utilco's subject matter experts, who were contracted personnel working for the UtilCo. This scenario certainly did not help in motivating subject matter experts to share freely their knowledge, as Accenture's Project Lead stated:

There were two activities that we not able to cover within those four weeks of KT time frame as the plan was. This was mostly because of people over there on the Client-site - not providing SMEs on the right time and some resistance from the SME's side to provide right knowledge transfer, discussions, and documentations, etc. (Interview with NT).

Accenture's Team Lead, who travelled to the UtilCo site for knowledge transfer sessions, echoed similar sentiments:

One particular hiccup we faced was that SMEs who give KT might not be from Client-site but might be working as a contractor. So, in that case, the availability of that particular contractor needs to be evaluated by Client before start of the KT. It happened many times that that particular contractor was busy, and as he is not Client employee but a Contractor, there are less restrictions on him that way to do the KT. Initial week we faced such issues and had to notif[y] [...] the senior client management (Interview with AP).

UtilCo's Transition Lead did not feel that subject matter experts' motivation played a role in delaying or influencing knowledge transfer sessions:

I think Service Provider put a lot of effort to get all the people together and knowledge. From my point of view, I had one person managing that process from our side. But there were not too many difficulties, I think, one or two persons had the feeling of why should I hand over my knowledge, but most people cooperated very well (Interview with WK).

Three significant challenges related to knowledge transfer emerged - an ambitious timeline due to the limited availability of UtilCo's contractors, the uncooperative attitude of these contractors, and a lack of appropriate project tracking tools. While resources from Apollo were ready to receive knowledge transfer, UtilCo's management was not yet fully prepared for it and had not sufficiently planned for the availability of their contractors, especially as these contractors had to continue working on their operational activities in addition to conducing knowledge transfer sessions. The knowledge transfer sessions for activities were initially planned in two stages of one month each, but this time-line was accelerated because of increased pressure due to the departure of key contractors from UtilCo who were not inclined to transfer their knowledge. Furthermore, due to the expedited planning, coupled with several unplanned, arbitrary knowledge transfer sessions, the necessary knowledge transfer tracking tools were not used. This created complications for both organizations in monitoring the current knowledge levels of Accenture's personnel which was partially alleviated by developing and using temporary tools.
Understanding transition performance

215 
SO

4,3

216
Despite UtilCo's perspective, Accenture interview participants claimed to face challenges with regard to this sub-factor. They also confirmed that once notified, these challenges were quickly resolved by the client.

4. Ramp-down of client IT personnel. A primary concern for the UtilCo during knowledge transfer sessions was the loss of knowledge as subject matter experts were laid off successively after providing knowledge transfer to Accenture personnel. They feared whether enough knowledge could be transferred within the stipulated period of four weeks. UtilCo's Transition Lead expressed this concern:

Well, one of the difficult things in these processes is the loss of knowledge. It is impossible to get knowledge out of people, who are doing the job for about 3,4 or 5 years. The basics you can transfer, but it is impossible to get the knowledge out of the mind (Interview WK).

Both parties acknowledged that knowledge transfer duration was slightly less than expected to transfer relevant knowledge, but both firms took significant measures to ensure monitoring and tracking of knowledge transfer sessions. UtilCo's Transition Lead stated:

What I did is that the handing over party should sign a form, and the receiving party should sign a form that they really exchanged the knowledge. So I may not have that much power over people who leave, but I have at least a formal signoff that the knowledge was given to Service provider firm and they accept that they have now enough knowledge (Interview with WK).

Accenture's Offshore Project Lead devised their own tools to capture and monitor the transfer of knowledge from subject matter experts:

Yes, I developed a tracker I have used particularly in this project; I asked my team lead [who was onsite] to put all the activities, to take charge of the activities, put the entire task into the tracker and share it across [with] me and Onshore Project Lead and whosoever is the point of contact there. So, basically, he put down all the major tasks which are going to be covered in the next whole four weeks of what are the areas that we are going to touch upon, what are going to be covered in the next whole four weeks of what are the areas that we are going to touch upon, what are the normal methodologies of transition. Is it a discussion? Is it a classroom session? Is it conference or whatever? (Interview with NT).

Another mechanism to monitor adequate transfer of knowledge was rating of Accenture personnel's capabilities by the subject matter experts in their subject areas after knowledge transfer period. Accenture's Offshore Transition Lead stated:

Essentially what we did is, at the start of the KT, we set up a plan that said, "I have to be at proficiency level III on that batch job monitoring process before I move on to further stage[s]". On [a] scale of 1 to 5 , we obviously cannot expect to be a 5; we would probably be a 3 or a 4 . So, proficiency is how we track, and that is really the tollgate that we are ready to support the applications or not. The proficiency is rated by a joined decision actually. It is really a mutual confirmation and agreement, and then sign-off to agree on to. All of the recordings happen on a tool, what proficiency am I? I could go in and change my proficiency to a 4, but essentially, the subject manager expert comes in and says he agrees that I am a 4 or I am a 3, I am a 2 (Interview with BN).

Based on the information from both UtilCo and Accenture informants, we did not find any evidence in this case study suggesting that ramp-down of UtilCo personnel was mismanaged or had influenced transition negatively. 


\section{Transition governance}

Transition governance is an important factor for transition performance. Several participants, during interviews and informal conversations, confirmed the importance of governance during transition, specifically, monitoring transition activities tasked to each staff member.

1. Involvement of cross-functional personnel. There is a need to ensure the availability/involvement of cross-functional personnel on both the UtilCo and the Accenture side, as shown in Figure 2. During transition, Accenture involved personnel with varied expertise from functional and technical to design and development. They also involved personnel with different experience levels, but the entire team composition was inclined towards younger personnel. UtilCo, on the other hand, also involved people from different functions - design, development, etc. from their IT department, but their numbers were limited due to multiple projects running concurrently. Furthermore, UtilCo did not involve personnel from business in the transition team.

2. Alignment of transition responsibility and commercial commitment. We found nothing specific in the case study data related to this sub-factor.

3. Alignment of transition responsibility and service delivery responsibility. Throughout the transition period, from the beginning, several monitoring mechanisms were incorporated into the engagement to compile the latest information from all relevant teams and to update transition and service delivery management periodically. These mechanisms included weekly (and some daily) teleconferences between onsite, offshore and UtilCo teams, as well as weekly status reports from offshore, and UtilCo's effort tracking system. Accenture implemented their global transition management tooling to support the transition and ensure a proper implementation of the transition project. Accenture's Offshore Transition Lead stated:

In terms of reporting, NT [Offshore Project Lead] sends out weekly status reports to our onshore team, and there are a couple of reports where onshore and offshore project leads work together to create some of the metrics, which ultimately goes to Client. What we do is that every week, onshore and offshore transition and project leads get onto a call to discuss the key issues and key action points and also go through the status reports. Offshore Project and Team Leads interact on a day-to-day basis with Onshore Project Lead for operations (Interview with $\mathrm{BN}$ ).

UtilCo's Transition Lead reported similarly:

We have a weekly project meeting to see how the transition is going. So for the entire period, we sit together with Onshore Transition and Project Lead along with some other people from our end to see how the process is going (Interview with WK).

4. Communication model. In addition to the three sub-factors of our framework, we find a potential fourth sub-factor: communication model. Owing to the involvement of three sites (UtilCo-site, Accenture's onshore-site and Accenture's offshore-site) during transition, communication and coordination among distributed team members was particularly challenging, especially during first few weeks of transition. Onshore and offshore communication constrained the relationship between teams due to lack of an appropriate protocol, as explained by Accenture's Offshore Project Lead:

Sometimes I observed that what was happening is that it was very easy for someone sitting with the client [onshore team], just getting some small issues, and call up person at offshore. My team lead here was getting really upset because they were getting a lot of calls on a daily
Understanding transition performance

217 
SO

4,3

218

basis without any advance knowledge about the calls. Maybe he is on lunch or something and he's getting a call or whatever issue that is happening. He was overwhelmed by th[at] kind of communication due to too [many] [...] phone calls or communication for small issues. It was for a phase of two or three weeks, it happened as things were on its peak, so I was a little concerned about that, so it became an issue for me, as my Team Lead was not looking very comfortable (Interview with NT).

This challenge in communication was handled by setting up formal communication processes between the onshore and offshore team. This included developing the role of Onshore Coordinator - who was a single point of contact (SPOC) for and to offshore. So, any communication from onshore personnel to offshore personnel was routed through the SPOC. Accenture's Onshore Project Lead stated:

There are two ways the offshore development team can get new work shifted to them. One of the ways is from the design team, and the other one from the operations team; both those teams have a single point of contact (SPOC) towards India. So, we have a SPOC who is sitting at client-site and we have a SPOC who is sitting at our onshore site (Interview with SV).

Another key challenge faced with regard to communication was who would initiate the conversations; for instance, whether onshore would explain to offshore what work to do, or whether offshore would explain their understanding of what work to do and onshore team would confirm. Accenture chose the second approach, as they found this type of initiation or communication flow between the two teams was crucial in order to avoid miscommunication. Accenture's Onshore Project Lead stated:

One of the things that we had in place is we had an operating model described, but once we got started, one thing we didn't describe is whose responsibility it was to initiate which step. This is one thing that we did have to learn and to start which is to make sure that we know whose responsibility if it's to plan which stage and whose responsibility is it to initiate certain calls and to plan those calls. And that's something that, well, we've now set in place or written down and shared with all those responsible people (Interview with SV).

\section{Retained organization}

Overall, retained organization had unexpectedly low importance considering it contains the responsibility of dealing with Accenture at an operational level both during and after transition. What may account for this finding is UtilCo's focus on retained organization prior to the implementation of the outsourcing engagement, as they had spent considerable time and effort in this area.

1. Timely communication of outsourcing plan. We found no specific instances of any inappropriate behavior or miscommunication of the outsourcing plan to UtilCo's IT personnel. Most of the IT personnel impacted by this outsourcing relationship were contractual workers employed by a third party and deputed at UtilCo for several years. This meant they were aware that their position was temporary in nature and renewed every few years.

2. Capabilities of the retained organization's personnel. UtilCo personnel who were part of the retained organization were provided new or modified roles. There was an overall restructuring of roles and responsibilities within UtilCo's IT function. These modifications in roles focused on changing the responsibilities of retained personnel from "doing" application development and maintenance work themselves to "monitoring" the service provider doing the work. This was reflected in comments by UtilCo's Transition Lead: 
So now we are into a situation where earlier our personnel did the designs themselves, now ours is much more of a review role. So the work changes from creating to reviewing; that's what they will do. That's [modifying or creating new roles to fit the outsourcing relationship] really indeed is the difficult part. One of the starting points, from our perspective, is to build a director's organization. We have identified and made new role descriptions for the entire IT supply organization, so we harmonized them across all sourcing teams (Interview with WK).

Since UtilCo personnel were not recruited with these roles in mind, they needed to undergo training and on-the-job learning experiences to adopt more of a managing role rather than doing the work themselves.

3. Alignment of the retained organization with the business. We found nothing specific with regard to this sub-factor. UtilCo's IT department and its processes did not change for the business users. The same process to submit any system issues or bugs remained. This contributed to overall alignment.

4. Alignment of the retained organization with the service provider's front office. Accenture chose to appoint a single-point-of-contact (SPOC) between their onshore and offshore teams to manage and track communication flow. UtilCo also adopted the SPOC model for aligning interactions between UtilCo's team and Accenture's team. UtilCo's Project Lead stated:

When we want a detailed estimation or we want to discuss planning, we have a single point of contact to the client - EP [service provider's Onshore Coordinator (Jan 2007)]. He does communication with the offshore team. So, whenever I want to know a status update or I want to talk to change or something like that, I just ask him and he will get the information from offshore and get it back to me (Interview with CR).

\section{Discussion}

This study provides the first detailed account of transition during offshore outsourcing. This discussion section reflects on the findings and includes practical implications. Within the project, both client and service provider personnel felt the transition was reasonably well managed but with some challenges. In this section, we explore the relative strength and weakness of each factor and their sub-factors within the investigated framework, along with their challenges and influence on the transition for Customer Project.

In our findings section, we concluded that there were two new variables at play "communication model" and "staged approach". These are additional variables not stated in our theoretical framework. "Communication model" relates to how communication and coordination is carried out among various distributed teams. This finding can be incorporated within the factor of transition governance under the sub-factor "involvement of cross-functional personnel from client and service provider firms" if we modify it to "capabilities and involvement of cross-functional personnel", as it was largely due to the lack of capabilities from which challenges related to communication model originated. We recommend clients to assess the communication structures, processes and capabilities of potential service providers prior to signing up for an outsourcing contract. The other finding - staged approach - seems to be a part of transition planning, but rather represents an important factor at a higher level and is related to the sourcing strategy of clients. The staged approach enables both the client company and the service provider to monitor more closely the progress of transition.
Understanding transition performance 
$\mathrm{SO}$

4,3

220

This closer monitoring might result in rectifying any potential gaps or issues identified during the transition. This is reducing the risk profile of transitions and avoids lock in and big surprise towards the end. Adopting a staged approach, to a large extend, depends on several factors, such as complexity of activities outsourced, and particularly in this case, lack of experience with offshore outsourcing. This project represented UtilCo's first offshore outsourcing experience, and the decision to adopt a staged approach existed even before they initiated contractual negotiations with service providers. The adjusted theoretical framework of transition performance (Figure 2) is transformed into the revised framework of transition performance (Figure 3).

Among the four factors - transition planning, knowledge transfer, transition governance and retained organization, we found that knowledge transfer and transition governance had a stronger positive influence on transition performance. The other two factors, while important, were not found to have a strong bearing on transition performance. This difference in factor strength is specific to the Customer Project we studied here.

There were several reasons underpinning the fact that knowledge transfer and transition governance had a strong influence in this case. First, the project presented critical knowledge transfer and transition governance challenges that had the potential to disrupt transition either by delaying its duration, by increasing involved costs, or by creating tensions or conflicts among distributed team members. We recommend to upfront agree on the availability of the involved resources in the transition planning (identification of resources) as not having the right resources available on time may potential lead to a poor transition planning and therefore, a poor transition performance. Knowledge transfer represents a one-time opportunity to transfer a client's system and functional knowledge, more so in Customer Project, as UtilCo's subject matter experts in charge of knowledge transfer were mostly third-party contractual personnel

Figure 3.

Revised framework of transition performance

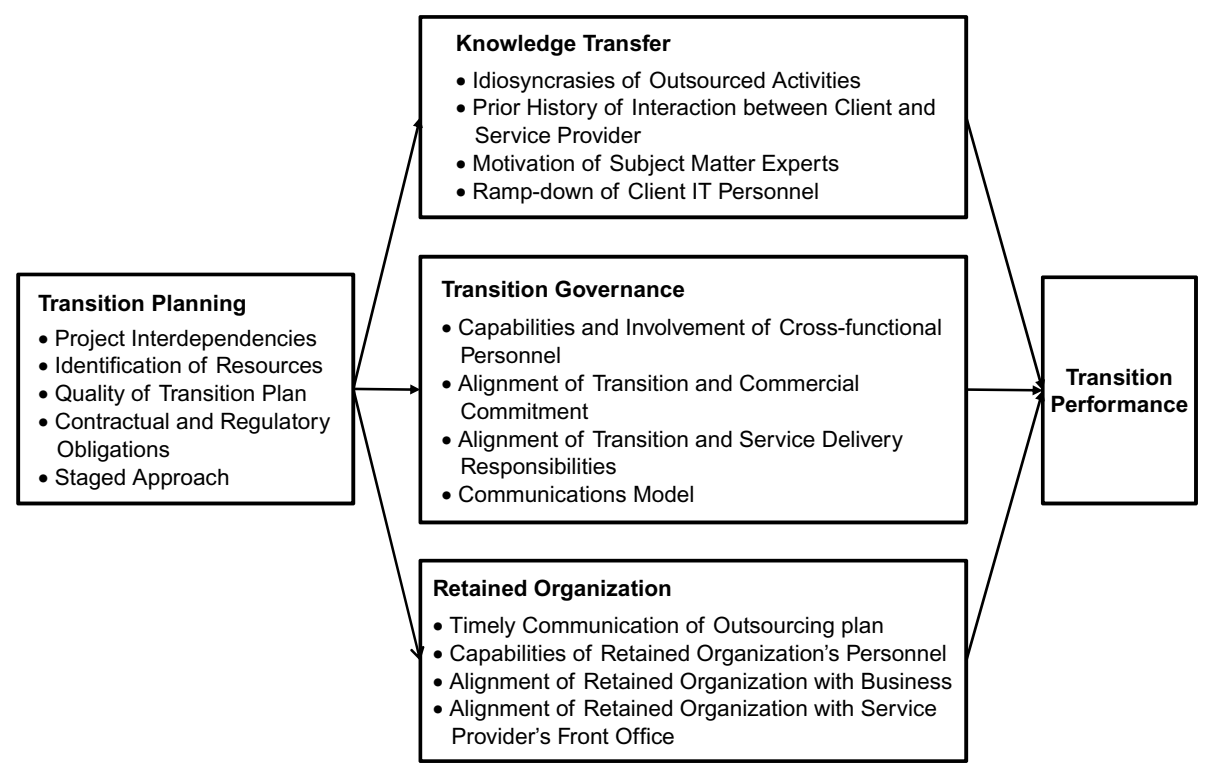


and planned to leave the firm after the knowledge transfer was complete. We would like to suggest the option of additional compensation (either monetary or in some other form) for the knowledge givers to ensure a proper knowledge transfer to the knowledge takers. In the investigated case study there was no additional compensation for the knowledge givers as the knowledge givers were predominantly the European employees of Accenture. Furthermore, Accenture made a significant monetary and time investment during the knowledge transfer phase in flying in a team from their offshore location and stationing them with the client. We do understand the financial motivation of service providers to increasingly rely on the remote knowledge transfer to save costs, however, too limited or poor knowledge transfer can seriously jeopardizing successful transition performance. In Customer Project, both parties reported the duration for transfer was short, and challenges with regard to experts' motivation in transferring their knowledge were found. While these challenges posed a threat for transition, they were absorbed mainly due to the experience and capabilities of the service provider personnel that received the knowledge transfer. We would recommend service provider to select senior transition management staff. This additional costs related to the more senior staff is well spend money and is likely to contribute to the success of the transition implementation.

Transition governance played a crucial role by facilitating transition goals by providing communication protocols for dispersed team members and by regularly monitoring transition progress, including any unforeseen circumstances that arose. In Customer Project, initially, poor governance frameworks and lack of personnel capabilities to implement these frameworks created unnecessary but critical challenges for transition to proceed smoothly. These challenges were mitigated by modifying frameworks to suit Customer Project and by clear communication from project leads to team members about the usage of these frameworks. The allocation of qualified client representatives to the transition project is essential. If required we recommend additional training the client representatives prior to the start of the implementation of the transition.

Second, both knowledge transfer and transition governance required significant joint effort from a combined team of client and service provider personnel to successfully implement elements within these factors. A lack of this joint effort at various times during the transition created friction among teams and posed a challenge for successful transition. Achieving a high level of joint effort was challenging due to the differences in motivation, organizational culture and expectations at both ends. To mitigate these challenges, both firms, especially UtilCo, implemented a framework of strong support from senior management for the project. We recommend to implement a steering committee including senior management representatives of the client and the service provider to ensure the right focus of the transition team members.

The other two factors within the Customer Project scope, transition planning and retained organization, were not found to have a particularly strong influence on transition performance in this instance. This could be explained by the fact that transition planning was taken as a given by UtilCo, i.e. they already expected Accenture to plan the transition appropriately, and Accenture had vast experience and proven methodologies to handle transition for the complexity level entailed by Customer Project. We recommend clients to ask for examples of transition plans and a transition approach in the selection process to ensure the potential service providers have sufficient experience in transitions.

\section{Understanding transition performance}

221 
SO

4,3

222
The retained organization factor had limited influence on transition performance in this project primarily because most UtilCo personnel affected by this outsourcing relationship were third-party contractual workers and it was unnecessary for them to be absorbed or retained within UtilCo's IT department. This reduced the need to invest resources in handling these personnel. There was only a relatively minor reorganization within UtilCo's IT department concerning role modifications for some direct-employ IT personnel. Furthermore, UtilCo had a previous relationship with Accenture, and this provided personnel at both ends with some expectations regarding each other's organizational culture, which facilitated their interaction during this project. Although neither of these two factors were found to have a strong influence on transition in the investigated project, we expect these factors to be extremely important for transition and to play a critical role in other projects and studies. We recommend clients to investigate the potential implications of an outsourcing decision prior to submitting the request for proposal and engaging with potential service providers. The potential implications should be included in the business case for outsourcing.

Although we found evidence of the importance and influence of each factor within the Customer Project case study, we did not find strong support for certain sub-factors within the initial framework, namely:

(1) contractual or regulatory obligations;

(2) idiosyncrasies of outsourced activities;

(3) alignment of transition and commercial responsibilities;

(4) timely communication of outsourcing plan; and

(5) alignment of retained organization with business.

These sub-factors were generated from the existing outsourcing literature. The primary reasons for their absence in Customer Project may be due to the moderate complexity level of the activities outsourced, involvement of a highly experienced and global service provider, and UtilCo's organizational culture. The activities outsourced were related to a well-known enterprise software product with limited customization. Furthermore, the service provider firm, Accenture, is one of the top players in the offshore outsourcing market and has significant experience with handling transitions.

\section{Conclusion}

In this paper, we focussed on determining and validating factors that influence transition performance in an offshore IT outsourcing relationship. Using an exploratory but in-depth and longitudinal case study of an offshore engagement, we assessed the framework involving four factors - transition planning, knowledge transfer, transition governance and retained organization. We found knowledge transfer and transition governance have a stronger influence on transition as compared to the other two factors. This was mainly due to two reasons:

(1) The critical challenges faced, within the scope of these factors, had higher potential to disrupt transition.

(2) Both these factors and their related issues required a significant joint and coordinated effort from client and service provider firms, thereby making their implementation challenging for transition. 
Several suggestions for future research can be made based on this research. First, scholars can focus on conducting an in-depth longitudinal case study on transition to corroborate whether our framework is generalizable beyond the context of two firms in our case study. Second, scholars can conduct a quantitative analysis to understand which factors and to what extend do these factors influence transition performance, for instance, to test the initial findings of this research by a more qualitative research approach, such as a survey. Third, scholars can focus on studying transition in the scenarios with multiple service providers. Furthermore, additional future research can include other offshore countries besides India. All these suggestions will improve the generalizability of the findings and improve the usability for practitioners.

\section{Note}

1. As requested by the client firm we are not allowed to reveal the name of the company.

\section{References}

Ambrose, C. and Matlus, R. (2005), "Following best practices to manage transitions in outsourcing relationships”, Report No. G00124899, Gartner, Stamford, CT.

Beulen, E. (2008), Global Sourcing, Tilburg University Press, Tilburg.

Beulen, E., Ribbers, P. and Roos, J. (2011), Managing IT Outsourcing, Governance in Global Partnership, 2nd ed., Routledge, London.

Beulen, E., Tiwari, V. and van Eck, E. (2009), "Understanding transition during offshore outsourcing: factor model of transition performance", paper presented at the Workshop on Global Sourcing, Keystone, CO, available at: www.globalsourcing.org.uk (accessed 19 March 2009).

Blumenberg, S., Wagner, H. and Beimborn, D. (2009), "Knowledge transfer processes in IT outsourcing relationships and their impact on shared knowledge and outsourcing performance", International Journal of Information Management, Vol. 29 No. 5, pp. 342-52.

Cadle, J. and Yeates, D. (2008), Project Management for Information Systems, 5th ed., Pearson Prentice-Hall, Upper Saddle River, NJ.

Carmel, E. (1999), Global Software Teams: Collaborating across Borders and Time Zones, Prentice-Hall PTR, Upper Saddle, NJ.

Carmel, E. and Beulen, E. (2005), "Managing the offshore transition”, in Carmel, E. and Tjia, P. (Eds), Offshoring Information Technology Sourcing and Outsourcing to a Global Workforce, Cambridge University Press, Cambridge.

Carmel, E. and Tjia, P. (2005), Offshoring Information Technology Sourcing and Outsourcing to a Global Workforce, Cambridge University Press, Cambridge.

Choudhury, V. and Sabherwal, R. (2003), "Portfolios of control in outsourced software development projects", Information Systems Research, Vol. 14 No. 3, pp. 291-314.

Cullen, S. and Willcocks, L. (2003), Intelligent IT Outsourcing: Eight Building Blocks to Success, Butterworth-Heinemann, Oxford.

Desouzaa, K. and Evaristob, J. (2006), "Project management offices: a case of knowledge-based archetypes”, International Journal of Information Management, Vol. 26 No. 5, pp. 414-23.

Dyer, J.H. and Singh, H. (1998), "The relational view: cooperative strategy and sources of interorganizational competitive advantage", Academy of Management Review, Vol. 23 No. 4, pp. 660-79.

\section{Understanding transition performance}

223 
$\mathrm{SO}$

4,3

224
Eisenhardt, K.M. (1989), "Building theories from case study research", Academy of Management Review, Vol. 14 No. 4, pp. 532-50.

Eisenhardt, K.M. and Graebner, M.E. (2007), "Theory building from case studies: opportunities and challenges", Academy of Management Journal, Vol. 50 No. 1, pp. 25-32.

Feeny, D. and Willcocks, L. (1998), "Core IS capabilities for exploiting information technology", Sloan Management Review, Vol. 39 No. 3, pp. 9-21.

Friedman, T. (2005), The World is Flat, 1st ed., Farrar, Straus \& Giroux, New York, NY.

Goles, T. (2006), "Capabilities for information systems outsourcing success", in Hirschheim, R., Heinzl, A. and Dibbern, J. (Eds), Informations Systems Outsourcing, Springer, Berlin.

Gottschalk, P. and Solli-Saether, H. (2006), Managing Successful IT Outsourcing Relationships, IRM Press, Hershey, PA.

Grimshaw, D. and Miozzo, M. (2009), "New human resource management practices in knowledge-intensive business services firms: the case of outsourcing with staff transfer", Human Relations, Vol. 62 No. 10, pp. 1521-50.

Gupta, A., Seshasai, S., Mukherji, S. and Ganguly, A. (2007), "Offshoring: the transition from economic drivers towards strategic global partnership and 24-hour knowledge factory", Journal of Electronic Commerce in Organizations, Vol. 5 No. 2, pp. 1-23.

Henderson, J.C. and Venkatraman, N. (1993), "Strategic alignment: leveraging information technology for transforming organisations", IBM Systems Journal, Vol. 32 No. 1, pp. 472-84.

Karimi, J., Somers, T.M. and Bhattacherjee, A. (2007), "The role of information systems resources in ERP capability building and business process outcomes", Journal of Management Information Systems, Vol. 24 No. 2, pp. 221-60.

Khan, N. and Fitzgerald, G. (2004), "Dimensions of offshore outsourcing business models", Journal of Information Technology Cases and Applications Research (JITCAR), Vol. 6 No. 3, pp. 35-50.

Kotlarsky, J., Oshri, I. and Willcocks, L. (2007), "Social ties in globally distributed software teams: beyond face-to-face meetings", Journal of Global Information Technology Management, Vol. 10 No. 4, pp. 7-34.

Lacity, M. and Hirschheim, R. (1993), Information Systems Outsourcing, Wiley, Chichester.

Lacity, M. and Rottman, J. (2008), Offshore Outsourcing of IT Work, Palgrave Macmillan, New York, NY.

Lacity, M. and Willcocks, L. (2000), "IT outsourcing relationships: a stakeholder perspective", in Zmud, R. (Ed.), Framing the Domains of IT Management Research: Glimpsing the Future Through the Past, Jossey-Bass, New York, NY.

Lacity, M., Khan, S. and Willcocks, L. (2009), "A review of the IT outsourcing literature: insights for practice”, Journal of Strategic Information Systems, Vol. 18 No. 3, pp. 130-46.

Lacity, M., Khan, S., Yan, A. and Willcocks, L. (2010), "A review of the IT outsourcing empirical literature and future research directions", Journal of Information Technology, Vol. 24 No. 4, pp. 395-433.

Levina, N. and Ross, J.W. (2003), "From the service provider's perspective: exploring the value proposition in information technology outsourcing", Management Information Systems Quarterly, Vol. 27 No. 3, pp. 331-64.

Miles, M.B. and Huberman, A.M. (1994), Qualitative Data Analysis: An Expanded Sourcebook, Sage, Thousand Oaks, CA.

Minton, S. (2010), "Worldwide IT spending historical databook", 1Q10, Pivot Table (Doc No. 223231), IDC Research Document, April. 
Oshri, I., Kotlarsky, J. and Willcocks, L.P. (2007), "Managing dispersed expertise in IT offshore outsourcing: lessons from Tata Consultancy Services", Management Information Systems Quarterly Executive, Vol. 6 No. 2, pp. 53-65.

Parikh, M. and Gokhale, G. (2006), "Legal and tax considations in outsourcing”, in Hirschheim, R., Heinz, A., Dibbern, J. (Eds), Informations Systems Outsourcing, Springer, Berlin.

Park, J., Im, K. and Kim, J. (2011), "The role of IT human capability in the knowledge transfer process in IT outsourcing context", Information \& Management, Vol. 48 No. 1, pp. 53-61.

Understanding transition performance

225

Quinn, J.B. (1999), "Strategic outsourcing: leveraging knowledge capabilities", Sloan Management Review, Vol. 40 No. 4, pp. 9-21.

Rivard, S. and Aubert, B. (2008), Information Technology, Advances in Management Information Systems, M.E. Sharp, New York, NY.

Robinson, M. and Iannone, P. (2007), "9 ways to avoid outsourcing failure, a three-part approach to maximizing the value of an IT outsourcing deal", CIO Magazine, 5 July, available at: www.cio.com.au/index.php/id;28653977;pp;1;fp;4;fpid;15 (accessed 28 October 2010).

Ross, C., Pohlmann, T. and Ester, O. (2005), “Confronting outsourcing myths”, Forrester Research Report, 13 December.

Verma, D. and Sinha, K.K. (2002), "Toward a theory of project interdependencies in high-tech R\&D environments", Journal of Operations Management, Vol. 20 No. 5, pp. 451-68.

Vroom, C. and Solms, R. (2004), "Towards information security behavioural compliance", Computers \& Security, Vol. 23 No. 3, pp. 191-8.

Wang, E., Barron, T. and Seidmann, A. (1997), "Contracting structures for custom software development: the impacts of informational rents and uncertainty on internal development and outsourcing", Management Science, Vol. 43 No. 12, pp. 1726-44.

Willcocks, L. and Lacity, M. (2006), Global Sourcing of Business and IT Services, Palgrave Macmillan, New York, NY.

Williamson, O. (1991), "Comparative economic organization: the analysis of discrete structural alternatives", Administrative Science Quarterly, Vol. 36 No. 2, pp. 269-96.

Yin, R. (2002), Case Study Research: Design and Methods, Sage, Newbury Park, CA.

\title{
Further reading
}

Niederman, F. (2005), "International business and MIS approaches to multinational organizational research: the cases of knowledge transfer and IT workforce outsourcing", Journal of International Management, Vol. 11 No. 2, pp. 187-200.

Sparrow, E. (2003), Successful IT Outsourcing: From Choosing a Provider to Managing the Project, Springer, London.

\begin{abstract}
About the authors
Professor Dr Erik Beulen is employed at Tilburg University in The Netherlands and holds the EquaTerra Global Sourcing Chair. He is also employed at KPMG EquaTerra. His research concentrates on outsourcing, offshore outsourcing, governance and the management of outsourcing relations. His papers have been published in journals such as Journal of Information Technology, European Management Journal, Information Technology \& People, Journal for Information Technology for Development and Communications of the Association for Information Systems. He is the author and co-author of various books on the subject of outsourcing and offshore outsourcing and the leading author of the book Managing IT Outsourcing, published by Routledge, UK. Erik Beulen is the corresponding author and can be contacted at: erik.beulen@uvt.nl
\end{abstract}


SO

4,3

226
Dr Vinay Tiwari works as a Process Manager in Global Functions IT at Shell in The Netherlands. He completed his doctoral dissertation at Rotterdam School of Management, Erasmus University. His research interests include outsourcing, transition and coordination. He has published articles in MIS Quarterly and presented papers at International Conference on Information Systems (ICIS) and Academy of Management Meetings.

Professor Dr ir Eric van Heck holds the Chair of Information Management and Markets at Rotterdam School of Management, Erasmus University, where he is conducting research and is teaching on the strategic and operational use of information technologies for companies and markets. He has co-authored or co-edited 14 books such as Making Markets (Harvard Business School Press, 2002) and Smart Business Networks (Springer, 2005). His articles were published in journals such as California Management Review, Communications of the ACM, Decision Support Systems, European Journal of Information Systems, Harvard Business Review, Information Systems Research, International Journal of Electronic Commerce, International Journal of Production Economics and Journal of Information Technology. He was ERIM's Director of Doctoral Education (2007-2009), a Visiting Professor at the Helsinki School of Economics (2002-2005) and the Ludwig-Maximilians University in Munich (Summer 2006), and a Visiting Scholar at MIT Sloan School of Management (Summer 2009).

To purchase reprints of this article please e-mail: reprints@emeraldinsight.com Or visit our web site for further details: www.emeraldinsight.com/reprints 
Appendix. List of interviewees

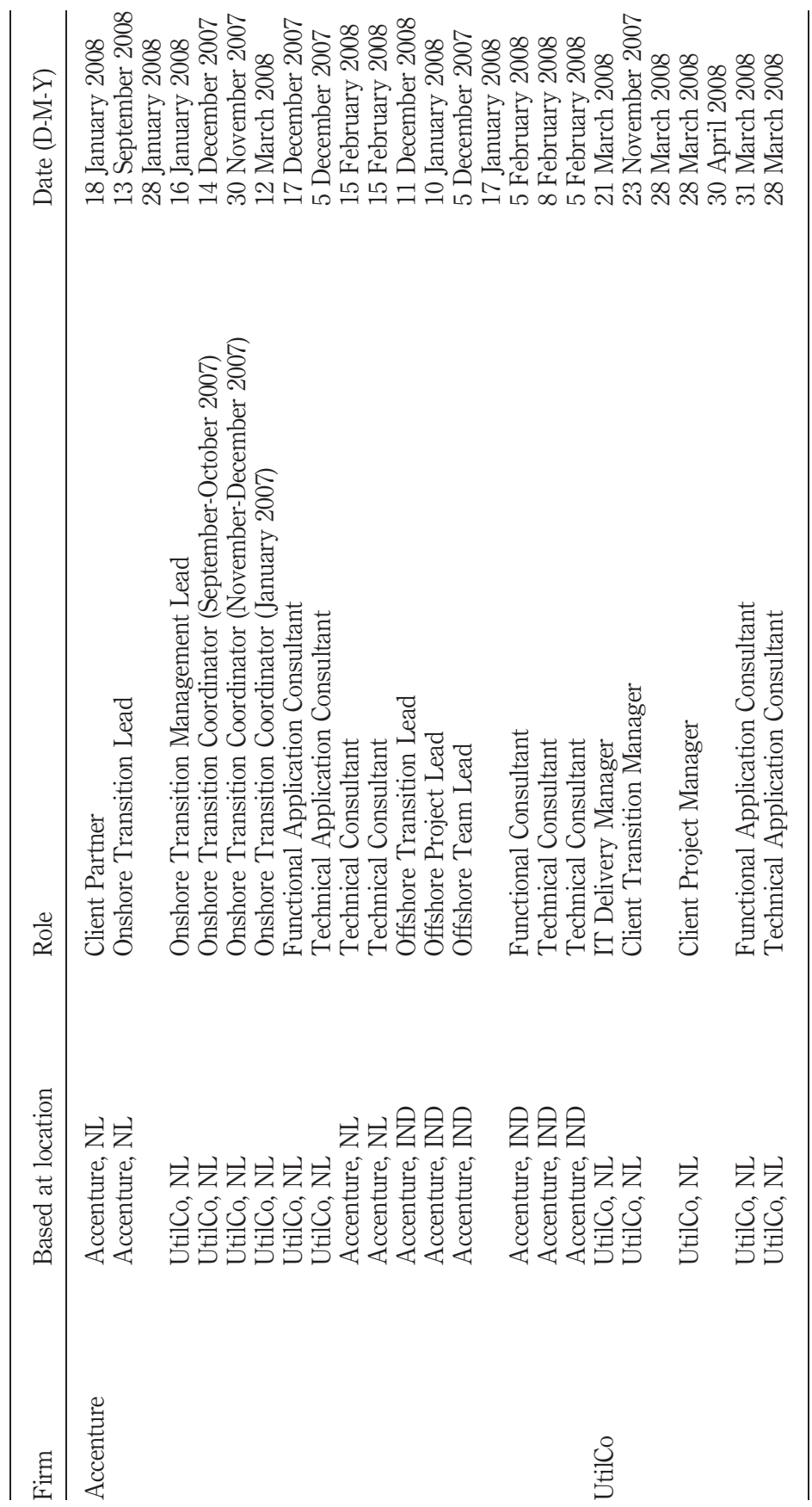

Understanding transition performance

227
Table AI. List of interviewees, their location, name, role and date of interview(s) 